\title{
A imaginação e seu processo formativo à luz da psicologia histórico-cultural
}

\author{
Imagination and its development in the light of cultural-historical \\ psychology
}

\author{
Mariana Cristina da Silva ${ }^{1}$ \\ Juliana Campregher Pasqualini ${ }^{2}$
}

\begin{abstract}
RESUMO
Tanto no senso comum como em algumas teorias psicológicas e pedagógicas, é assumido o pressuposto de que a imaginação da criança é mais rica e desenvolvida que a do adulto. $\mathrm{O}$ presente artigo contrapõe-se à tese do embotamento natural da imaginação no curso da periodização do desenvolvimento, submetendo o fenômeno da imaginação à análise científica de orientação históricocultural. O objetivo central é demonstrar que a imaginação é um processo psíquico que se desenvolve e se complexifica à medida da também complexificação da atividade da pessoa no mundo. Tendo em vista elucidar o processo formativo da imaginação, abordamos sua especificidade em relação às demais funções psíquicas; pontuamos e analisamos suas expressões ativa e passiva; e apresentamos as técnicas imaginativas, em um esforço de sistematização das determinações e traços essenciais desse processo psíquico decodificados por Vigotski (2009), Vygotski (2014), Ignatiev (1960), Petrovski (1960), Repina (1974) e Rubinstein (1978). Concluímos o artigo focalizando implicações pedagógicas da discussão apresentada.
\end{abstract}

Palavras-chave: Imaginação. Psicologia histórico-cultural. Ensino escolar.

\begin{abstract}
Both in common sense and in some psychological and pedagogical theories, the assumption that the imagination of the child is richer and more developed than that of the adult is assumed. This article opposes the thesis of the natural blunting of the imagination in the course of the periodization of development, subjecting the phenomenon of imagination to the scientific analysis of historical-cultural orientation. The central objective is to demonstrate that the imagination is a psychic process that develops and becomes complex as grows the complexity of the activity of the person in the world. In order to elucidate the formative process of the imagination, we approach its specificity in relation to the other psychic functions; punctuate and analyze their active and passive expressions; and present imaginative techniques, in an effort to systematize the determinations and essential features of this psychic process decoded by Vygotsky (2014), Ignatiev (1960), Petrovski (1960), Repina (1974) and Rubinstein (1978). We conclude the article focusing pedagogical implications of the presented discussion.
\end{abstract}

Keywords: Imagination. Cultural-historical psychology. School teaching.

${ }^{1}$ Pedagoga e Mestra pelo Programa de Pós-Graduação em Educação Escolar. Faculdade de Ciências e Letras, UNESP/Araraquara. marianacsilva1@gmail.com.

${ }^{2}$ Psicóloga, Mestre e Doutora em Educação Escolar pela UNESP/Araraquara, com pós-doutorado pela Faculdade de Educação da UNICAMP. Docente do Departamento de Psicologia da UNESP/Bauru e do Programa de Pós-Graduação em Educação Escolar da UNESP/Araraquara. juliana.pasqualini@unesp.br. 


\section{Introdução}

A criança é, em nossa sociedade, usualmente concebida com um ser naturalmente imaginativo. Afirma-se, por exemplo, que o mundo das crianças "[...] é diferente do mundo dos adultos porque sua imaginação lhes oferece possibilidades muito mais criativas e inesperadas" (sítio Portal da Família ${ }^{3}$ ). Na mesma linha, difunde-se a ideia de que "os pequenos são naturalmente imaginativos e só precisam de um pequeno empurrão de seus pais e familiares para desenvolver essa habilidade de forma saudável e completa" (blog Viva Arte Viva $\left.^{4}\right)$. A imaginação é, assim, comumente compreendida como uma função psíquica inerente à criança, que seria potencialmente rica no decorrer da infância mas podada com o passar do tempo, perfazendo uma (curiosa) espécie de involução.

Não apenas no senso comum mas também em algumas teorias psicológicas e pedagógicas, é assumido o pressuposto de que a imaginação da criança é mais rica e desenvolvida que a do adulto. Em diálogo crítico com essa concepção, apresentamos, no presente artigo, reflexões acerca da função psíquica imaginação a partir dos pressupostos defendidos por autores da psicologia histórico-cultural. Contrapondo-nos à tese do embotamento natural da imaginação no curso da periodização do desenvolvimento humano, nosso objetivo é demonstrar que a imaginação é um processo psíquico que se desenvolve e se complexifica à medida da também complexificação da atividade da pessoa no mundo, sendo, portanto, a imaginação adulta (tendencialmente) mais desenvolvida do que a infantil.

As discussões aqui apresentadas comunicam parte dos resultados da dissertação de mestrado da primeira autora (SILVA, 2019), elaborada sob orientação da segunda, na qual se analisou o desenvolvimento da imaginação na idade pré-escolar em relação com a atividade guia do período, a saber, a brincadeira de papéis sociais. Os nexos entre a complexificação da atividade infantil e o desenvolvimento da imaginação no período pré-escolar foram

\footnotetext{
${ }^{3}$ https://www.portaldafamilia.org/artigos/artigo758.shtml

${ }^{4}$ https://www.macunaima.com.br/vivaarteviva/como-estimular-a-criatividade-do-seu-filho-vejaestas-4-dicas/
} 
investigados e sistematizados por meio de estudo teórico-bibliográfico de obras selecionadas de autores vinculados à Escola de Vigotski.

Tendo em vista elucidar o processo formativo da imaginação, destacamos, no presente artigo, suas determinações e traços essenciais decodificados por Vigotski (2009), Vygotski (2014), Ignatiev (1960), Petrovski (1960), Repina (1974) e Rubinstein (1978). Para tanto, abordamos a especificidade da imaginação em relação às demais funções psíquicas; pontuamos e analisamos suas expressões ativa e passiva; e apresentamos as técnicas imaginativas, buscando evidenciar que elas se desenvolvem e, portanto, não são acessíveis em suas máximas expressões de desenvolvimento à criança pequena. Concluímos o artigo focalizando implicações pedagógicas da discussão apresentada, defendendo, em diálogo com os pressupostos da pedagogia histórico-crítica, que é preciso que o trabalho educativo, desde a escola de Educação Infantil, desenvolva a imaginação em suas máximas possibilidades.

Com o esforço de síntese teórica que aqui apresentamos à comunidade acadêmica, somamo-nos aos esforços de pesquisadores que têm se dedicado a combater concepções naturalizantes e idealizadas de infância e do desenvolvimento humano a partir da análise científica da capacidade cultural humana de transformar imagens, com destaque aos trabalhos de Saccomani (2016), que analisa a relação entre criatividade e ensino escolar, de Giannoni (2018), que sistematiza e analisa a trajetória histórica das investigações histórico-culturais sobre imaginação na União Soviética, e de Martins (2013), que aborda o desenvolvimento do processo funcional imaginação no contexto de seu já clássico estudo sobre o desenvolvimento do psiquismo e a educação escolar.

\section{A gênese da imaginação na história do gênero humano}

Para conceituar a imaginação como função psíquica e elucidar seu processo formativo, partimos da compreensão de que o psiquismo humanizado constitui-se de funções psíquicas afetivo-cognitivas, a saber, sensação, percepção, atenção, memória, linguagem, pensamento, imaginação e emoções e sentimentos. Tais processos psíquicos são responsáveis pela formação da imagem subjetiva da realidade objetiva, operando de modo interfuncional (MARTINS, 2013). 
Tal proposição expressa uma ontologia materialista histórica, que afirma a existência objetiva dos fenômenos a serem captados ou refletidos subjetivamente na forma de imagem (representação) na/pela atividade consciente, que institui sistemas ideativos de mediação da relação sujeito-mundo. Vale pontuar que o conceito de psiquismo como responsável por engendrar a imagem subjetiva do real não se confunde com a projeção linear do objeto na consciência, mesmo porque o conceito de reflexo psíquico não se circunscreve à captação empírica imediata dos fenômenos, sendo a categoria atividade (social) nuclear para compreensão desse processo. O pressuposto em tela é que a atividade (social) engendra a consciência, e esta a regula. O estudo científico das funções psíquicas, incluída a imaginação, relaciona-se diretamente ao processo de formação da consciência.

Nesse enquadre, uma primeira premissa para se compreender a capacidade humana de imaginar é não tomá-la isoladamente, mas como processo funcional que integra a totalidade do psiquismo humano, estando, portanto, submetida às leis gerais explicativas da formação do psiquismo. Dentre essas leis destacamos, ao lado da já mencionada interfuncionalidade, a historicidade e a requalificação dos processos psíquicos elementares do organismo homo sapiens mediante processos de objetivação e apropriação da cultura que instituem o ser social. A psicologia histórico-cultural compreende a imaginação não com um dado inato ao psiquismo humano, mas como conquista do desenvolvimento históricocultural humano-genérico. Neste sentido, podemos afirmar que as características fundamentais desta função psíquica foram historicamente desenvolvidas enquanto demandas da atividade vital humana, ou seja, enquanto exigências da atividade de trabalho.

Ignatiev (1960, p. 308) permite uma aproximação à relação entre imaginação e trabalho ao destacar a dimensão teleológica da atividade de trabalho, que envolve a ideação prévia do resultado almejado a guiar as ações humanas:

Pelo trabalho o homem influi sobre o mundo que o rodeia, muda a realidade com um objetivo determinado e segundo um plano. $\mathrm{O}$ homem, antes de fazer algo, representa o que é necessário fazer e como o vai fazer. Antes de construir alguma coisa material, o homem a cria mentalmente em sua cabeça. A atividade humana se diferencia da conduta dos animais em que o homem, quando 
trabalha, representa muito antes em sua mente o que se propõe conseguir e todos os atos que tem que realizar para isto. Os animais, por outro lado, fazem mudanças na natureza sem nenhuma intenção de sua parte e sem representar previamente o resultado que terá sua conduta (IGNATIEV, 1960, p. 308, tradução nossa).

A atividade de trabalho institui algo até então inexistente na relação animal-natureza, a saber, a possibilidade do surgimento de objetos primeiro idealmente e depois objetivamente. É fato que os animais agem sobre a natureza. A grande diferença reside, como nos lembra o clássico excerto marxiano que compara o pior arquiteto à melhor abelha, no fato de que os animais constroem apenas com base em suas necessidades biológicas e de acordo com as suas capacidades naturais, sendo incapazes de antecipar o produto final de suas construções. Neste sentindo, nem abelhas nem aranhas imaginam ou traçam ideativamente um plano de ações que deverá ser seguido para que atinjam seus objetivos finais. Como sempre constroem movidas por suas necessidades naturais e guiadas por programações comportamentais inatas, as aranhas sempre construirão teias e jamais uma colmeia, do mesmo modo que a abelha só poderá fazer uma colmeia e nunca uma teia ou qualquer outra coisa. O mesmo vale para as formigas, os pássaros, os castores ou qualquer outro animal, pois os animais não podem desprender-se dos limites impostos por suas respectivas hereditariedades. No limite, os seres humanos, dadas as condições objetivas e subjetivas para tal, podem construir "o que quer que seja”. Destarte, podemos afirmar de modo conclusivo que nenhum animal possui a capacidade de imaginar, sendo esta capacidade exclusivamente humana: "na dimensão teleológica, pela qual a atividade humana se diferencia de todas as demais formas vivas de atividade, radica a gênese da imaginação [...]" (MARTINS, 2013, p.228).

A tese em tela é que a natureza teleológica da atividade de trabalho, ou seja, a atividade dirigida a fins específicos, exigiu do psiquismo humano a capacidade de imaginar e, ao colocar em movimento essa função psíquica, possibilitou seu desenvolvimento. O nexo entre trabalho e imaginação fica evidenciado quando se constata que o trabalho pressupõe a imagem antecipada do produto da atividade (MARTINS, 2013), ou seja, pressupõe um objeto que existe primeiro idealmente antes de ganhar existência material ou objetiva. Essa 
imagem antecipada do produto da atividade é formada, psiquicamente, mediante combinações e alterações de imagens prévias, produzindo outras e novas imagens. "A imagem assim produzida pode operar como modelo psíquico a ser conquistado como produto da atividade orientada por ele [...]" (MARTINS, 2013, p.227).

Em suma, a imaginação surgiu e se desenvolveu na atividade de trabalho como uma exigência mesma da natureza desta atividade humana. Dialeticamente, a imaginação em formas desenvolvidas possibilitou o desenvolvimento e a requalificação da própria atividade. Tal formulação expressa uma das leis gerais que explicam a formação do psiquismo, que diz respeito justamente à relação entre a atividade humana e o desenvolvimento de funções psíquicas. Trata-se do postulado segundo o qual as funções só se desenvolvem "funcionando" no interior de atividades que as requeiram, o que significa dizer que é a atividade social que mobiliza e provoca o desenvolvimento das capacidades do psiquismo, as quais, uma vez desenvolvidas, retroagem sobre a atividade, possibilitando sua complexificação.

\section{A imaginação como processo funcional e sua especificidade}

O esforço de apreensão das particulares capacidades que compõem o sistema psíquico humano mostra-se importante para revelar o movimento da atividade consciente e suas "engrenagens", sempre considerando-se o caráter interfuncional e sistêmico do psiquismo. Orientado por essa perspectiva, Vygotski (2014) debruçou-se sobre o problema da especificidade da imaginação, inserindose nos debates acerca da imaginação e dialogando com autores que lhe eram contemporâneos. Atesta o autor:

[...] a imaginação não repete em iguais combinações e formas impressões isoladas, acumuladas anteriormente, mas sim que constrói novas séries a partir das impressões acumuladas anteriormente. Com outras palavras, o novo aportado ao próprio desenvolvimento de nossas impressões e as mudanças destas para que resulte uma nova imagem, inexistente anteriormente, constitui, como é sabido, o fundamento básico da atividade que denominamos imaginação (p. 423, tradução nossa). 
Neste sentido, compreendemos que a especificidade da imaginação em relação às outras funções psíquicas é a criação de novas imagens. Portanto, podemos afirmar que o fundamento basilar da imaginação é a transformação.

Cumpre destacar, conforme pontua Giannoni (2018), que os estudos acerca da imaginação constituíram-se como uma necessidade no período pósrevolucionário na União Soviética, no bojo do esforço de elaboração coletiva de uma psicologia que visasse a "[...] criação do novo homem e da nova mulher socialista [...]" (p. 54). Esse olhar para as condições históricas nas quais as formulações teóricas que aqui se apresentam acerca do processo psíquico imaginação é decisivo pois "[...] devemos compreender que a psicologia na União Soviética não nasceu de um fato quimérico, nem tão pouco em um ambiente harmonioso [...] A psicologia soviética foi fruto e resultado de um processo histórico [...]" (idem). Portanto, se no cerne do processo imaginativo está a transformação, como acabamos de pontuar, podemos afirmar que o desenvolvimento desta função psíquica, e os estudos concernentes a ela, ganharam relevância epistemológica como uma necessidade forjada em um momento histórico no qual se colocava como problema a transformação no âmbito pessoal e societário, isto é, na formação de cada indivíduo singular, e, principalmente, da sociedade soviética.

Neste sentido, de acordo com a definição de Petrovski (1985), "a imaginação é a capacidade de criar novas imagens sensoriais ou racionais na consciência humana sobre a base de transformar as impressões recebidas da realidade" (p. 321, tradução nossa). Rubinstein (1978), por sua vez, afirma que "a imaginação significa uma separação da experiência passada, uma reforma do dado e, sobre esta base, a produção de novas imagens, que ao mesmo tempo são produto da atividade criadora do homem e exemplo dela" (p. 361, tradução nossa).

Dado o caráter transformador da imaginação postulado por Petrovski, podemos também destacar a conceituação proposta por Ignatiev (1960) que afirma que "a imaginação é a criação de imagens com forma nova, é a representação de ideias que depois se transformam em coisas materiais ou em atos práticos do homem" (p. 308, tradução nossa). A partir desta definição traçada pelo autor, destacamos a imaginação como a possibilidade de primeiro 
representar mentalmente o que depois será transformado em objeto material ou em ação do indivíduo.

Se afirmamos que a imaginação promove a transformação das imagens prévias (passado) e indicamos a possibilidade de que estas se expressem na atividade prática (futuro), fica estabelecida a intrínseca, complexa e multifacetada relação entre imaginação e realidade, o que desautoriza qualquer tratamento idealista que desgarra esse processo psíquico da prática social. Se a imaginação suplanta a experiência sensorial prévia e a própria realidade nela refletida, explica Martins (2013), ao mesmo tempo encontra na realidade seu ponto de apoio e condição de existência, seu ponto de partida e seu ponto de chegada.

Para compreensão acerca da relação entre imaginação e realidade no tocante à dimensão de projeção ao futuro, torna-se relevante a distinção que estabelecem os autores em estudo entre imaginação passiva e ativa. Se a imaginação se realiza mediante transformações de imagens, cabe observar que essas transformações podem ocorrer de maneira ativa ou passiva. Conforme Rubinstein (1978, p.365, tradução nossa), "a diferença entre a "passividade" e a "atividade" não é outra coisa que precisamente a diferença do grau do premeditado e do consciente".

Petrovski (1985) afirma que a imaginação passiva caracteriza-se pela criação de imagens que não vêm a se materializar concretamente e por "programas de conduta" que não se efetivam. O referido autor atesta que, nestes casos, a imaginação pode funcionar como um "escape temporário" ao que ele denomina de "reino das representações" em uma tentativa, por exemplo, de fugir momentaneamente de problemas que parecem insolúveis ao indivíduo. Neste sentido, destaca-se que este processo vincula-se diretamente às necessidades que se expressam para cada indivíduo singular.

Ainda de acordo com Petrovski, a imaginação passiva pode ser autoprovocada deliberadamente, expressando o que ele denominou de imaginação passiva intencionada. Assim, se for desvinculada da vontade que esteja orientada à sua materialização, o autor afirma que se chama devaneio. Embora seja normal almejar coisas alegres e melhores, Petrovski (1985, p. 323) considera que a predominância de devaneios institui ou expressa uma vida ilusória: 
Se a pessoa é passiva, se não luta por um futuro melhor e sua vida atual é difícil e faltam alegrias, com frequência se cria uma vida ilusória, inventada na qual se satisfazem completamente suas necessidades, onde ele tudo pode, onde ocupa uma posição impossível de alcançar no momento atual e na vida real (idem, tradução nossa).

Neste sentido, cabe pressupor que essa imaginação passiva intencionada que não orienta à materialização e às ações reais descrita por Petrovski pode ser pensada em inter-relação com as condições objetivas de vida dos indivíduos. Em uma sociedade dividida em classes sociais e organizada pelo modo de produção capitalista, a tendência é que as pessoas não encontrem condições objetivas para a efetivação daquilo que é imaginado como uma vida melhor, tal como apontado pelo autor.

Entretanto, Petrovski aponta também a existência da imaginação passiva não intencionada. Segundo o autor, este tipo específico de imaginação ocorre quando há uma diminuição da atividade consciente do indivíduo, a saber, em estados de sonolência, de $\operatorname{sonhos}^{5}$ ou, inclusive, em estados patológicos da consciência, como em alucinações, por exemplo. Podemos pensar, então, que a imaginação passiva não intencionada caracteriza-se pela máxima expressão daquilo que é elementar relacionado à imaginação humana. Neste sentido, esta imaginação está muito mais relacionada a um processo involuntário, de caráter mais biológico do que cultural, embora, certamente, o conteúdo que se expressa por esse tipo específico de imaginação também seja cultural.

Ainda acerca da expressão passiva da imaginação, Rubinstein (1978) afirma que nas formas inferiores e primitivas da imaginação, a transformação

\footnotetext{
${ }^{5}$ Julgamos necessário aqui um adendo no sentido de esclarecer que Petrovski refere-se duas vezes ao sonho como expressão imaginativa. Na primeira, afirmamos, o sonho se caracteriza por seu aspecto puramente fisiológico relativo à reorganização das imagens de maneira absolutamente involuntária que ocorre quando os indivíduos estão dormindo. Porém, o autor também se refere ao sonho como sinônimo, poderíamos dizer, de "projeto de vida". Neste sentido, diferente da condição passiva que representa o sonho em seu aspecto biológico, "o sonho é condição imprescindível para materializar as forças criadoras da pessoa orientadas à transformação da realidade" (PETROVSKI, 1985, p. 331, tradução nossa). Portanto, essa segunda conceituação acerca do sonho implica compreendê-lo como força motriz para a atividade. Destarte, esse sonho do qual fala Petrovski está intimamente relacionado à realidade e relacionado ao reino das necessidades humanas, diferentemente do sonho em sua condição orgânica elementar.
} 
das imagens ocorre de maneira involuntária. Essa transformação é impulsionada e caracterizada pelo baixo (ou inexistente) grau de consciência do indivíduo. $\mathrm{O}$ referido autor aponta que a exposta forma de imaginação só é possível em níveis muito inferiores do desenvolvimento da consciência ou em estados de sopor e de sonhos. Ainda de acordo com ele, "nos níveis inferiores, a mudança das imagens se produz espontaneamente e por si mesmo; nos superiores, desempenha um papel cada vez maior a consciente e ativa postura do homem na formação de suas imagens" (p. 364, tradução nossa). Ignatiev (1960) também destaca neste aspecto da imaginação denominando de involuntária essa expressão na qual não há intencionalidade por parte do indivíduo na criação de imagens. De acordo com este autor, as formas mais simples de imaginação ocorrem quando não há uma intenção especial na formação das imagens.

Diferente da imaginação passiva, os autores identificam a existência da imaginação ativa, ou voluntária, na denominação de Ignatiev. Petrovski (1985) afirma que ao contrário da passiva, a imaginação ativa caracteriza-se por materializar-se na realidade e por programas de conduta que também se efetivam. O referido autor diferencia a imaginação ativa em dois tipos. O primeiro deles é a imaginação reconstrutiva. De acordo com ele, a imaginação reconstrutiva é "a imaginação que se baseia em um sistema de imagens correspondentes à descrição" (PETROVSKI, 1985, p. 323, tradução nossa). Como expressão deste tipo específico de imaginação, o autor cita o exemplo da literatura, dos mapas geográficos, das descrições históricas etc., nas quais é necessário que o indivíduo reconstrua por intermédio da imaginação o que está representado nos livros, nos desenhos ou em relatos.

O que Petrovski chamou de reconstrutiva, Ignatiev (1960) denominou de imaginação representativa. De acordo com o autor, este tipo de imaginação representa aquilo que se apresenta como novo para cada indivíduo singular, mas não, especificamente, para o gênero humano. Assim, a imagem é formada com base na descrição verbal ou em "forma condicional" mediante desenhos, esquemas, notas musicais etc. De acordo com Ignatiev, a imaginação representativa está presente em diversos âmbitos da vida e em especial no ensino escolar no qual o autor destaca a necessidade de ricas descrições para a formação de "imagens vivas" por parte dos alunos. 
Nesta mesma perspectiva, Rubinstein (1978) denomina este tipo de imaginação acerca da qual discorreram Petrovski e Ignatiev de imaginação reprodutora. O que está posto de acordo com o referido autor é a capacidade de a imaginação reproduzir aquelas imagens que já estão dadas previamente. Esta reprodução, da forma como o autor a coloca, deve ser pensada como a apropriação pelo indivíduo daquelas objetivações humanas criadas ao longo da história da humanidade. Neste sentido, cabe ressaltar que reprodução não tem aqui um caráter pejorativo que remeta a uma atitude passiva por parte de quem reproduz. Tanto não é verdade, que Rubinstein classifica a imaginação reprodutora no âmbito da imaginação ativa. Sobre esta perspectiva, Saccomani (2016) afirma que:

Com efeito, reprodução e criação são processos dialéticos. A apropriação também é reprodução, na medida em que reproduz, no indivíduo, as objetivações humanas historicamente acumuladas. $\mathrm{E}$, por conseguinte, essas apropriações criam, no indivíduo, novas necessidades e a possibilidade da criação (p. 61).

Portanto, embora as nomenclaturas possam ser distintas, os autores convergem para a concepção de um tipo de imaginação ativa a partir da qual os indivíduos podem reproduzir ou reconstituir imagens acerca das objetivações outrora produzidas por outros indivíduos. Como anteriormente afirmado, esse também é um tipo ativo de imaginação, por possibilitar a reprodução dos traços essenciais das produções humanas e da realidade, permitindo com que os indivíduos se insiram na cultura humana, o que de modo algum se caracteriza como ato passivo ou acrítico. Esse tipo específico de imaginação é fundamental, pois "permite ao indivíduo superar os limites da experiência particular e, ao fazêlo, participar ativamente nos processos de aprendizagem e na compreensão de experiências alheias” (MARTINS, 2013, p. 229).

Da passagem acima citada também nos importa destacar que em unidade dialética com a reprodução está a criação. Ainda no âmbito da imaginação ativa, Petrovski (1985), Ignatiev (1960) e Rubinstein (1978) atestam a existência do que os três autores chamaram de imaginação criadora.

De acordo com Petrovski (1985), a imaginação criadora, diferentemente do que ele chamou de reconstrutiva, pressupõe a criação independente de novas 
imagens. Essas novas imagens materializam-se em produtos originais. Ainda de acordo com o autor, a imaginação criadora tem origem no trabalho e é condição para a criação técnica, artística e etc. Ademais, a imaginação criadora manifestase como uma operação com imagens ativas e orienta-se pela busca da satisfação das necessidades do indivíduo. Retomando Vigotski (2009) podemos afirmar que "na base da criação há sempre uma inadaptação da qual surgem necessidades, anseios e desejos" (p. 40). Concernente à imaginação criadora, Petrovski afirma que quando este tipo de imaginação é predominante, podemos pensar que isto é um indicativo de um nível mais elevado do desenvolvimento da personalidade do indivíduo.

Ignatiev (1960) define que "a criação, ou atividade criadora, é a função em virtude da qual se obtém produtos novos, originais, que se fazem pela primeira vez" (p. 313, tradução nossa). Ademais, nesta perspectiva, o autor afirma que a atividade criadora é motivada por necessidades sociais, ou seja, são as necessidades que emergem da prática social que demandam e impulsionam a criação de algo novo, outrora inexistente. É também nesta direção que Rubinstein (1978) compreende a imaginação criadora, afirmando que é ela que, de fato, cria novas imagens.

Ademais, vale ainda destacar que não é possível considerar que a criação seja o produto de um processo advindo da "imaginação livre". Sobre esta perspectiva, Ignatiev (1960) afirma que "o feito de criar não é um jogo livre da imaginação, que não exige um grande trabalho, e que algumas vezes é pesado" (p. 316, tradução nossa). Ainda em relação à imaginação criadora e à sua consequente materialização, cabe ressaltar que nenhuma criação prescinde das condições objetivas nas quais ocorre. Neste sentido, Vigotski (2009) afirma que: "a imaginação costuma ser retratada como uma atividade exclusivamente interna, que independe das condições externas ou, no melhor dos casos, que depende delas apenas na medida em que elas determinam o material com o qual a imaginação opera" (p. 41). Ainda de acordo com o autor:

Qualquer inventor, mesmo um gênio, é sempre um fruto de seu tempo e de seu meio. Sua criação surge de necessidades que foram criadas antes dele e, igualmente, apoia-se em possibilidades que existem além dele. Eis porque percebemos uma coerência rigorosa 
no desenvolvimento histórico da técnica e da ciência. Nenhuma invenção ou descoberta científica pode emergir antes que aconteçam as condições materiais e psicológicas necessárias para seu surgimento. A criação é um processo de herança histórica em que cada forma que sucede é determinada pelas anteriores. (idem, p. 42).

Essa passagem de Vigotski é fundamental para inserir a criação humana no interior da própria história e da atividade humana levando em consideração as condições objetivas, mas também subjetivas, para tal. Tendo esta perspectiva, Ignatiev (1960) destaca o papel indispensável exercido pela imaginação nos mais diversos tipos de criações humanas, como na produção e na invenção técnica, na científica e na artística. Petrovski (1985) também dá destaque ao papel da imaginação nas criações artística e científica. Já Rubinstein (1978) dá especial ênfase à criação artística.

Quadro 1 - Categorização das formas da imaginação

\begin{tabular}{|c|c|c|}
\hline \multirow{2}{*}{$\begin{array}{c}\text { Imaginação } \\
\text { passiva }\end{array}$} & Não intencionada & $\begin{array}{c}\text { Transformação/ criação involuntária de } \\
\text { imagens, que ocorre quando há uma } \\
\text { diminuição da atividade consciente do } \\
\text { indivíduo (em estados de sonolência, sonhos e } \\
\text { estados patológicos da consciência, como em } \\
\text { alucinações). }\end{array}$ \\
\hline & Intencionada & $\begin{array}{l}\text { Criação de imagens que não vêm a se } \\
\text { materializar concretamente e por "programas } \\
\text { de conduta" que não se efetivam, podendo } \\
\text { funcionar como escape temporário a } \\
\text { problemas, conflitos e padecimentos. Quando } \\
\text { desvinculada até mesmo da vontade de } \\
\text { materialização, configura-se como devaneio. }\end{array}$ \\
\hline \multirow[t]{2}{*}{$\begin{array}{c}\text { Imaginação } \\
\text { ativa/ } \\
\text { voluntária }\end{array}$} & $\begin{array}{l}\text { Reprodutora/ } \\
\text { reconstrutora/ } \\
\text { representativa }\end{array}$ & $\begin{array}{l}\text { Capacidade de reconstituir imagens } \\
\text { previamente existentes, fixadas nas } \\
\text { objetivações da cultura (literatura, descrições } \\
\text { históricas, mapas geográficos, etc.), vinculada } \\
\text { àquilo que se apresenta como novo para cada } \\
\text { indivíduo singular, mas não para o gênero } \\
\text { humano. Tem especial importância no ensino } \\
\text { escolar. }\end{array}$ \\
\hline & Criadora & $\begin{array}{c}\text { Criação de novas imagens que materializam-se } \\
\text { em produções originais. É motivada por } \\
\text { necessidades da prática social e produz-se na } \\
\text { dependência de condições objetivas e } \\
\text { subjetivas. }\end{array}$ \\
\hline
\end{tabular}

Fonte: Elaborado pelas autoras.

É possível afirmar que da imaginação depende toda criação humana, já que tudo o que existe, conforme apontou Vigotski (2009) é “imaginação 
cristalizada". Isso significa afirmar que tudo aquilo que foi e é criado pelo homem é produto desta função psíquica exclusivamente humana, em conexão interfuncional com os demais processos que compõe o sistema psíquico.

$\mathrm{Na}$ verdade, a imaginação, base de toda a atividade criadora, manifesta-se, sem dúvida, em todos os campos da vida cultural, tornando também possível a criação artística, a científica e a técnica. Nesse sentido, necessariamente, tudo o que nos cerca e foi feito pelas mãos do homem, todo o mundo da cultura, diferentemente do mundo da natureza, tudo isso é produto da imaginação e da criação humana que nela se baseia (VIGOTSKI, 2009, p. 14).

Entretanto, mesmo que os autores coloquem a importância da imaginação nos tipos de criação anteriormente citados, cabe ressaltar que quando nos referimos à imaginação e à capacidade de criação humana é preciso ficar claro que não estamos levando em consideração apenas as grandes produções humanas. Vigotski (2009) afirma que, certamente, há imaginação em cada ato humano, haja vista a necessidade de que as pessoas têm de também criar, ainda que coisas pequenas, na vida cotidiana como imposição da vida e da sobrevivência, ou, poderíamos acrescentar, como forma de expressão criativa da própria individualidade. O referido autor afirma que "segundo uma analogia feita por um cientista russo, a eletricidade age e manifesta-se não só onde há uma grandiosa tempestade e relâmpagos ofuscantes, mas também na lâmpada de uma lanterna de bolso" (VIGOTSKI, 2009, p. 15). A supracitada analogia apontada por Vigotski deixa evidente que, portanto, há imaginação em cada pequena criação humana e que cada pequena criação também carrega criações alheias à medida que o indivíduo se apropria delas, ainda que possamos diferenciar estas criações de maneira qualitativa e em relação à influência que determinadas criações exercem na vida em coletividade.

A criação, na verdade, não existe apenas quando se criam grandes obras históricas, mas por toda parte em que o homem imagina, combina, modifica e cria algo novo, mesmo que esse novo se pareça a um grãozinho, se comparado às criações dos gênios. Se levarmos em conta a presença da imaginação coletiva, que une todos esses grãozinhos não raro insignificantes da criação individual, veremos que grande parte de tudo o que foi criado pela humanidade pertence exatamente ao trabalho criador anônimo e coletivo de inventores desconhecidos (VIGOTSKI, 2009, p. 15-16). 
Das questões expostas, é fundamental destacar que em todo tipo de criação há um aspecto comum a eles: em qualquer criação humana é necessário que a imaginação suplante o imediatamente percebido. Especificamente em relação à criação Martins (2013) afirma que "entre a imaginação criativa e a percepção se estabelece uma relação de natureza especial, na qual o artista não se aliena do campo perceptual, mas o transforma à medida que subtrai dele seus aspectos casuais, acessórios, deixando à mostra sua essência, muitas vezes oculta” (p. 231). Neste sentido, a imaginação é capaz de "romper" com a percepção imediata tanto no sentido de representar por intermédio de imagens aquilo com que o indivíduo nunca teve contato quanto para criar novas imagens tidas como originais e antes inexistentes. Esse é o pressuposto característico desta função psíquica, pois como afirma Rubinstein (1978) "as imagens com as que opera o ser humano não se limitam à reprodução do diretamente percebido. $\mathrm{O}$ ser humano pode ver também "diante de si" em imagens o que não percebeu diretamente [...]" (p. 361, tradução nossa).

\section{4 "Técnicas da imaginação" ou de como a imaginação imagina}

Buscamos analisar a imaginação enquanto a formação de novas imagens a partir das transformações daquelas imagens já prévias advindas da experiência humana e humano-genérica. Entretanto, como se dá esse processo? De fato, como a imaginação imagina? Tendo esta questão em foco, analisaremos a partir principalmente das contribuições de Petrovski (1985), Rubinstein (1978) e Vigotski (2009) quais as operações mentais necessárias à imaginação, isto é, quais as "técnicas", tal como denominado por Rubinstein, usadas pela imaginação para imaginar.

Petrovski (1985) afirma que a imaginação é função de caráter analíticosintético, assim como a percepção, a memória e o pensamento (p. 324). O referido autor atesta que por intermédio da análise é possível identificar os traços gerais e essenciais daquilo que se percebe afastando aquilo que não se configura como tal. A supracitada análise culmina em uma síntese que, segundo Petrovski (1985), implica a criação de um padrão por meio do qual são agrupados os objetos que 
mesmo diversos "não excedem as margens de uma 'medida de semelhança' determinada” (p. 324, tradução nossa).

Especificamente em relação à função imaginativa, Petrovski (1985) afirma que "a análise e a síntese na imaginação têm outra orientação e no curso do processo de operação ativa das imagens descobrem novas tendências" (p. 324, tradução nossa). Isso significa afirmar que como já pontuamos, a imaginação não se limita àquelas imagens já existentes, mas possui como fundamento primordial a transformação dessas imagens.

Cabe ressaltar que esta transformação não ocorre de maneira fortuita ou aleatória, mas segundo regras e preceitos. Versando sobre esta questão, Rubinstein (1978) afirma que "a transformação da realidade na imaginação não é nenhuma modificação arbitrária. Tem suas normas, que se manifestam nos típicos métodos da transformação" (p. 369). Ademais, é preciso destacar que a imaginação possui profunda relação com as necessidades oriundas da prática social. Como bem pontua Giannoni (2018) "[...] é na prática que está a necessidade da criação de uma nova máquina, de novas teorias ou ainda obras de arte. Portanto, além da prática ser um critério de verdade, também é aquilo que condiciona as necessidades para as criações humanas" (p. 74).

A primeira das normas apontadas por Rubinstein (1978) é a combinação que se manifesta pela "vinculação dos elementos dados na experiência a combinações novas, mais ou menos desacostumadas" (p. 369). Especificamente em relação à combinação, tanto Rubinstein quanto Vigotski citam como exemplo a composição da personagem Natacha do romance "Guerra e Paz" de Leon Tolstói. Vigotski (2009) menciona que Tolstói, referindo-se à forma de criação da personagem, teria afirmado “"Peguei a Tânia [sua cunhada]”, diz ele, "remoí com a Sônia [sua esposa], então, saiu a Natacha"” (p. 34). Ao destacar traços característicos de ambas as mulheres o escritor pode obter uma síntese que fez surgir a composição de sua personagem. Isto é, Natacha é a síntese obtida por intermédio da análise da personalidade das mulheres que serviram de "inspiração" a Tolstói , e que a partir do ato de criação ganha "vida própria".

A segunda forma pela qual a imaginação transforma as imagens é a aglutinação. Tanto Petrovski quanto Rubinstein referem-se a esta forma específica. Petrovski (1985) afirma que a aglutinação pressupõe "a "fusão" de 
distintas qualidades, propriedades e partes que não se unem na vida diária" (p. 325, tradução nossa). Assim, o referido autor destaca que por intermédio desta "técnica imaginativa" são formadas muitas imagens de contos ou de criações técnicas, como por exemplo, o acordeão, uma "mistura" das propriedades do acordeão e do piano. Rubinstein, convergindo com a definição acima exposta, afirma que a aglutinação é utilizada sobremaneira nas artes. O referido autor exemplifica com os monumentos advindos da arte egípcia e com a arte de indígenas norte-americanos, além de citar a "figura alegórica" do prazer e da dor de Leonardo da Vinci. A partir dos exemplos, Rubinstein afirma que a aglutinação não une elementos de forma aleatória, mas segundo uma tendência que dá sentido à esta união e ao produto obtido dela.

Como técnica usada pela imaginação podemos citar também a acentuação destacada por Rubinstein e denominada de agudização por Petrovski. Segundo Rubinstein, a acentuação é um processo por meio do qual alguns traços ou características são enfatizados, intensificados, ou, como a própria denominação sugere, acentuados, ou seja, destacados em relação aos demais. Esse destaque é dado àquilo que se demonstra como o mais característico ou essencial. Petrovski também conceitua a agudização a partir do destaque dado à determinadas características principais. Ambos os autores exemplificam esta técnica imaginativa a partir da caricatura, ou seja, um desenho que busca aquilo que de mais distintivo e específico há em algo ou alguém para dar destaque.

Em relação a este tipo de técnica, Rubinstein afirma que há duas possibilidades que se apresentam. Uma delas diz respeito ao caráter quantitativo, ou seja, tanto ao aumento hiperbólico quanto à redução. $\mathrm{O}$ referido autor exemplifica com as histórias fantásticas e com os contos nos quais há heróis com forças descomunais, figuras gigantes ou muito pequenas etc. Além disso, ele aponta a possibilidade na qual a desproporção externa evidenciada pelo aspecto quantitativo à qual nos referimos seja reveladora de aspectos internos das personagens. Cabe ressaltar que se Rubinstein afirma que essa possibilidade de aumento e de redução é um subtipo da acentuação, Petrovski afirma que a hiperbolização é uma técnica imaginativa específica.

De acordo com o autor, a hiperbolização não se caracteriza somente pelo aumento ou pela diminuição do objeto, mas também pela variação que promove 
na quantidade de partes ou na mistura delas. Em relação a esta outra característica apontada, Petrovski dá como exemplo Durga, a deusa de muitas mãos presente na mitologia hindu, e o dragão de sete cabeças.

Especificamente em relação a esta hiperbolização, Vigotski também traça algumas considerações por intermédio do que ele chama de exagero. $\mathrm{O}$ referido autor afirma que "a paixão das crianças pelo exagero, do mesmo modo que a dos adultos, tem fundamentos internos muito profundos, que, em grande parte, consistem na influência que o nosso sentimento interno tem sobre as impressões externas" (VIGOTSKI, 2009, p. 37). Neste sentido, o autor afirma que os indivíduos costumam ter interesse por tudo aquilo que é extraordinário e incomum. Ademais, tudo aquilo que é exacerbado permite o exercício imaginativo com valores com os quais os indivíduos estão desacostumados, pois não estão disponíveis de maneira direta na experiência.

Outro tipo de técnica imaginativa apontada por Petrovski é a esquematização. De acordo com o autor, "no caso de que as representações, das quais se constrói a imagem da fantasia, se unem, moderam suas diferenças e os traços semelhantes passam ao primeiro plano, se produz a esquematização" (PETROVSKI, 1985, p. 325-326, tradução nossa). Podemos inferir, que por intermédio da esquematização elementos diferentes anulam suas diferenças no sentido de edificar algo por meio de suas semelhanças. O referido autor cita como exemplo de esquematização o uso que os artistas fazem de elementos do mundo vegetal para a criação de ornamentos. A título de exemplo, poderíamos pensar em uma coroa feita de flores e ramos. Os elementos são diversos, mas suas diferenças ficam em segundo plano no sentido de valorizar aquilo que de semelhante eles têm para a composição do resultado do produto final.

A última técnica por intermédio da qual a imaginação imagina é a tipificação, segundo Petrovski, ou estereotipação, segundo Rubinstein. Ambos os autores convergem no sentido de considerar esta técnica relacionada à generalização. Petrovski (1985) afirma que "a identificação do mais essencial, do que se repete em feitos, em certo grau homogêneos, e a materialização destes em uma imagem concreta é característica da tipificação" (p. 326, tradução nossa). Rubinstein, referindo-se ao que ele denomina de estereotipação, afirma que se trata de uma "generalização específica". Portanto, ao referirem-se à 
generalização, os autores estão afirmando a centralidade daqueles traços essenciais e universais presentes nos fenômenos. O destaque desses traços permite generalizar, ou seja, encontrar as regularidades presentes na realidade. Cabe ressaltar que a imaginação não é a única responsável por esse processo. A generalização depende, sobremaneira, da linguagem e do pensamento em seus intercruzamentos, como buscaremos demonstrar adiante. O que é específico da imaginação no tocante à capacidade de generalização é que esta função psíquica, ao valer-se dela, procede à transformação das imagens tendo em vista a formação de novas imagens imaginativas.

Destarte, a imaginação criadora pressupõe a transformação das imagens com as quais a imaginação imagina. Como afirmamos, esta transformação não ocorre de maneira livre ou solta, mas de acordo com normas e regras e a partir das técnicas imaginativas que permitem o trato com as imagens. São estas, portanto, as operações que permitem a formação de novas conexões o que possibilita a formação das imagens imaginativas.

\section{Conclusão: a imaginação como processo funcional que se desenvolve ao longo da vida mediante obutchenie}

Partimos do pressuposto de que os seres humanos, ao nascerem, não possuem as características fundamentais que os fazem pertencentes ao gênero humano. Todos os indivíduos nascem pertencentes à espécie humana, mas tornar-se de fato um indivíduo humanizado é condição consequente à apropriação da cultura. Nesta perspectiva, Saviani (2012) afirma que “[...] o que não é garantido pela natureza tem que ser produzido historicamente pelos homens, e aí se incluem os próprios homens. Podemos, pois, dizer que a natureza humana não é dada ao homem, mas é por ele produzida sobre a base da natureza biofísica [...]” (p. 13).

É, portanto, neste sentido que Saviani (2012) define que “[...] trabalho educativo é o ato de produzir, direta e intencionalmente, em cada indivíduo singular, a humanidade que é produzida histórica e coletivamente pelo conjunto dos homens [...]" (p. 13). Assim, compreendendo o trabalho como uma atividade teleológica, isto é, que antecipa mentalmente o produto final, podemos afirmar que o trabalho educativo é, também, uma atividade essencialmente imaginativa. 
Nesta mesma perspectiva, Ignatiev (1960) afirma que "[...] o pedagogo "projeta" (segundo a expressão de Makarenko) a personalidade da criança, vislumbra o caminho de sua formação [...]" (p. 314, tradução nossa).

Nesta perspectiva, a partir do que foi exposto, compreendemos que fica evidente a inconsistência de afirmar que a imaginação estaria plena e ricamente desenvolvida na infância em comparação a do adulto. Estaríamos, portanto, diante de um raro fenômeno de desenvolvimento ao contrário, ou, no limite, nem poderíamos chamar de desenvolvimento, mas de involução e esfacelamento da capacidade imaginativa. Entretanto, conforme pontuamos, nem todos os adultos alcançam os mais altos patamares no desenvolvimento imaginativo, em especial no contexto da sociedade do trabalho alienado, que impõe obstáculos intransponíveis ao pleno desenvolvimento das capacidades humanas, produzindo embotamento e mantendo as pessoas reféns das circunstâncias imediatas de luta pela subsistência. Não obstante, esta constatação não nos permite afirmar que estamos diante de qualquer atributo imaginativo natural e inerente com o qual algumas pessoas, por sorte, nascem e outras, por algum infortúnio, não são agraciadas. O que está em voga, portanto, são as condições objetivas de vida e de educação.

Assim, a suposta superioridade da imaginação infantil e sua perda ao longo da vida expressam somente a aparência do fenômeno imaginativo. É claro que não podemos descartar que, de fato, a sociedade capitalista pode impossibilitar o pleno desenvolvimento da imaginação, dadas não só as condições nas quais ocorre o trabalho alienado, mas também ao promover condições sociais e educativas que não garantem o desenvolvimento do indivíduo em suas máximas possibilidades.

A tão difundida ideia de que a imaginação está mais desenvolvida nas crianças que nos adultos somente pode justificar-se pelo fato de que a imaginação se desenvolve antes que o pensamento abstrato e que o peso relativo da mesma na vida do indivíduo é maior na infância que posteriormente. A 'fuga da realidade' nas fantasias infantis consiste principalmente que a criança não pode ter em conta as leis da realidade objetiva, que desconhece, pelo que violenta facilmente a realidade da vida. A aparente abundância das fantasias infantis é na realidade, em sua maior parte, mais expressão da debilidade de seu pensamento crítico que 
a da força de sua imaginação. (RUBINSTEIN, 1978, p. 373, tradução nossa).

Martins (2013, p.239) contribui para aclarar essa questão destacando a relação entre imaginação e a periodização da formação de conceitos. Pontua que:

A suposta superioridade da imaginação infantil outra coisa não é, senão mais uma expressão do pensamento sincrético e do pensamento por complexos, preponderantes nessa fase do desenvolvimento infantil, na qual a imaginação é fundamentalmente emocional e calcada em elementos associados por inferência subjetiva.

Ainda segundo Martins (2013), gradualmente a imaginação conquista uma nova forma, cujo conteúdo é radicalmente oposto à forma infantil, passando a apoiar-se no conhecimento dos nexos objetivos que encontram-se efetivamente na base dos fenômenos: à medida do desenvolvimento do pensamento abstrato e lógico-discursivo como forma mais complexa de representação da realidade, a imaginação galga novos graus de realismo, podendo materializar-se nos produtos dos projetos humanos. A conquista do realismo nos processos imaginativos é, em nosso entendimento, condição para a imaginação ativa. Nesta perspectiva, Saccomani (2016) atesta que as vinculações entre a imaginação e o pensamento “[...] são, portanto, tão fortes que se pode afirmar que não há imaginação sem pensamento abstrato! Assim, os conteúdos desse tipo de pensamento constituemse em matéria prima para a imaginação" (p. 73).

De acordo com Repina (1974) é possível afirmar que o maior realismo na imaginação das crianças precisa ser produzido. Entretanto, como se dá esse processo? A resposta pode ser encontrada na relação que se estabelece necessariamente entre experiência prévia - conhecimento da realidade imaginação, ou seja, “[...] o produto da atividade imaginativa será tão rico quanto for o conhecimento que o indivíduo tenha sobre o conteúdo imaginado [...]" (ANJOS, 2017, p. 281). Neste sentido, Repina (1974) afirma que:

[...] o trabalho desenvolvido referente ao enriquecimento das representações de pré-escolares, por meio da familiarização com aspectos diferentes da realidade, demonstra que a ampliação do escopo das representações exerce uma influência no conteúdo e no 
número das imagens imaginativas [...] (p. 262, tradução nossa, grifos nossos).

Nessa direção, Rubinstein afirma que é necessário fazer com que a criança conheça novas facetas da realidade objetiva que em sua insuficiente experiência cotidiana lhe são desacostumadas. Assim, Rubinstein (1978) afirma conclusivamente que "[...] a criança deve sentir que também o desacostumado pode ser real [...]” (p. 377, tradução nossa). Ampliar sua experiência significa inserir a criança gradativamente no interior das produções humano-genéricas que não lhe são cotidianas. Isso porque, na vida cotidiana, a rigor, os seres humanos não apresentam necessidades além daquelas que o próprio cotidiano alienado impõe, sendo, portanto, objetivações em si. Assim, Rubinstein se refere àquelas objetivações que sintetizam a história humana de maneira rica, ou seja, aqueles conteúdos expressos pelas ciências e pelas artes, especialmente. Destarte, são essas novas facetas da realidade que ampliarão a experiência da criança ampliando, portanto, as relações de sua imaginação com a realidade objetiva.

A imaginação em suas formas mais desenvolvidas, diante de todos seus atributos e características, apresenta-se sempre a partir da realidade objetiva, e quanto maior for o conhecimento do indivíduo sobre a realidade, maior será a expressão de sua imaginação (ANJOS, 2017, p. 281).

Tendo em voga a perspectiva acima elucidada, Repina (1974) afirma que maneira conclusiva que:

[...] o realismo da imaginação da criança requer uma ativa educação. É imperativo que a imaginação da criança seja desenvolvida em conexão com o enriquecimento de suas experiências pelo conhecimento da realidade e que ela não retorne a uma fantasia infrutífera que sirva como um escape da realidade (p. 261, tradução nossa).

Destarte, compreendemos que as implicações desta proposição são fundamentais para o ensino escolar. A escola, incluso a escola de Educação Infantil, deve ter como norte o desenvolvimento da imaginação da criança por intermédio da ampliação de suas experiências, isto é, por intermédio do enriquecimento daquilo que a criança conhece acerca da realidade, fazendo com 
que ela se engaje em atividades (lúdicas, de estudo, etc.) que provoquem e dirijam o processo formativo da capacidade de transformar imagens em suas máximas possibilidades.

Para a psicologia concreta de Vigotski, o desenvolvimento infantil se produz como resultado dos processos educativos, ou, na terminologia original do autor, da obutchénie, o engajamento do aprendiz em atividade orientada por pares mais desenvolvidos, cujo conteúdo desafia as capacidades já conquistadas pelo psiquismo. Essa lei geral é válida para explicar o processo formativo particular da imaginação, guiando a intervenção educativa. Assim, a compreensão científica da natureza e da gênese da capacidade humana de transformar imagens, incluindo as formas da imaginação e suas técnicas, representa um instrumental teórico do qual pode lançar mão o/a professor/a ao traçar objetivos pedagógicos e selecionar conteúdos e formas de ensino, organizando a atividade do estudante de modo a promover o desenvolvimento da imaginação em suas máximas possibilidades. A transmissão-assimilação do conhecimento historicamente acumulado requer o desenvolvimento da capacidade de imaginar, ao mesmo tempo que, dialeticamente, provoca e propicia esse desenvolvimento. Em síntese, o pleno desenvolvimento da imaginação é, para o ensino escolar, a um tempo condição e resultado.

\section{Referências}

ANJOS, R. E. O desenvolvimento histórico-cultural da imaginação na adolescência e a educação escolar. Temas em Educação e Saúde, Araraquara, v. 13, n. 2, p. 271-285, jul./dez. 2017. doi: 10.26673/rtes.v13.n2.juldez.2017.9602.

GIANNONI, A. P. Uma história da psicologia soviética explicitada pelas abordagens da função imaginativa (1917-1960). 2018. 250 f. Dissertação (Mestrado em Psicologia) - Faculdade de Ciências Humanas, Universidade Federal de Mato Grosso do Sul, Campo Grande, 2018.

IGNATIEV, I. E. La imaginación. In: SMIRNOV, A. A.; LEONTIEV, A. N.; RUBinstein, S. L.; TIEPLOV, B. M. (org.). Psicologia. México: Grijalbo, 1960.

MARTINS, L. M. O desenvolvimento do psiquismo e a educação escolar: contribuições à luz da psicologia histórico-cultural e da pedagogia históricocrítica. Campinas: Autores Associados, 2013. 
MARX, K. O Capital: crítica da economia política. São Paulo: Boitempo, 2013. (Livro I: o processo de produção do capital).

PETROVSKI, A. V. La imaginación. In: PETROVSKI, A. V. Psicologia General: manual didáctico para los institutos de pedagogia. Moscú: Progreso, 1985.

REPINA, T. A. Development of imagination. In: ZAPOROZHETS, A. V.; ELKONIN, D. B. The psychology of preschool children. Cambridge: MIT Press, 1974.

RUBINSTEIN, S. L. La imaginación. In: RUBINSTEIN, S. L. Principios de psicología general. México: Grijalbo, 1978.

SACCOMANI, M. C. da S. A criatividade na arte e na educação escolar: uma contribuição à pedagogia histórico-crítica à luz de Georg Lukács e Lev Vigotski. Campinas: Autores Associados, 2016.

SAVIANI, D. Pedagogia histórico-crítica: primeiras aproximações. Campinas: Autores Associados, 2012.

SILVA, M. C. da. O desenvolvimento da imaginação e a atividade da criança em idade pré-escolar. 2019. 199 f. Dissertação (Mestrado em Educação Escolar) - Faculdade de Ciências e Letras, Universidade Estadual Paulista, Araraquara, 2019.

VIGOTSKI, L. S. Imaginação e criação na infância. São Paulo: Ática, 2009.

VYGOTSKI, L. S. Obras Escogidas II: problemas de psicología general. Madrid: Antonio Machado Libros, 2014. 